\title{
(6) OPEN ACCESS \\ IQ and alcohol-related morbidity and mortality among Swedish men and women: the importance of socioeconomic position
}

\author{
Sara Sjölund, ${ }^{1}$ Tomas Hemmingsson, ${ }^{2,3}$ Jan-Eric Gustafsson, ${ }^{4}$ Peter Allebeck ${ }^{1}$
}

\begin{abstract}
- Additional material is published online only. To view please visit the journal online (http://dx.doi.org/10.1136/jech2014-204761).

${ }^{1}$ Division of Social Medicine, Department of Public Health Sciences, Karolinska Institutet, Stockholm, Sweden

${ }^{2}$ Institute of Environmental Medicine, Karolinska Institutet Stockholm, Sweden

${ }^{3}$ Centre for Social Research on Alcohol and Drugs, Stockholm University, Stockholm, Sweden ${ }^{4}$ Department of Education, Göteborg University, Gothenburg, Sweden
\end{abstract}

\section{Correspondence to}

Sara Sjölund, Division of Social Medicine, Department of Public Health Sciences, Karolinska Institutet, Plan 8, Tomtebodavägen $18 \mathrm{~A}$ Stockholm 171 76, Sweden; sara.sjolund@ki.se

Received 5 August 2014 Revised 23 January 2015 Accepted 25 January 2015 Published Online First 10 July 2015

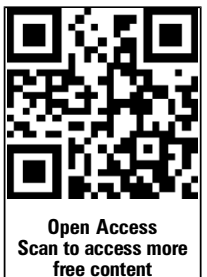

CrossMark

To cite: Sjölund $S$ Hemmingsson $\mathrm{T}$, Gustafsson J-E, et al. J Epidemiol Community Health 2015:69:858-864.

\section{ABSTRACT}

Aims To investigate the association between

intelligence in childhood and later risk of alcohol-related disease and death by examining (1) the mediating effect of social position as an adult and (2) gender as a

possible moderator.

Design Cohort study.

Setting and participants 21809 Swedish men and women, born in 1948 and 1953, from the Swedish

"Evaluation Through Follow-up" database were followed until 2006/2007.

Measurements IQ was measured in school at the age of 13 and alcohol-related disease and death (International Classification of Disease codes) were followed from 1971 and onwards.

Findings We found an increased crude HR of 1.23 (95\% Cl 1.18 to 1.29) for every decrease in group of IQ test results for alcohol-related admissions and 1.14 (95\% Cl 1.04 to 1.24) for alcohol-related death. Social position as an adult was found to mediate both outcomes. Gender was not found to moderate the association. However, adjusting for socioeconomic position lowered the risk more among men than among women.

Conclusions There was an inverse, graded association between IQ and alcohol-related disease and death, which at least partially was mediated by social position as an adult. For alcohol-related death, complete mediation by socioeconomic position as an adult was found. Gender does not moderate this association. The role of socioeconomic position may differ between the genders.

\section{INTRODUCTION}

Previous findings have shown an inverse association between intelligence and all-cause mortality, ${ }^{12}$ as well as intelligence and specific somatic ${ }^{34}$ and psychiatric outcomes. ${ }^{5-9}$ Similar findings have been reported for an association between intelligence and alcohol-related problems. ${ }^{10-18}$ However, the findings have not been consistent. The variation in results in previous studies could be dependent on type of alcohol-related outcome used: an inverse association has been demonstrated for binge drinking, alcoholism, alcohol abuse and dependence. ${ }^{4812}$ A positive association between IQ and perceived problems of drinking alcohol as defined by the CAGE questionnaire has also been shown. ${ }^{10} 15$ The CAGE questionnaire consists of four questions asking if the person (1) ever felt need to Cut down on drinking, (2) been Annoyed when criticised for drinking, (3) felt Guilty about drinking and (4) needed an Eye-opener in the morning. For the association between intelligence and alcohol-related outcomes, there are two issues of particular interest: (1) if the association is sex-specific and (2) how they are associated. The lack of knowledge regarding these two issues has been highlighted and discussed in the previous literature. ${ }^{219}$

The association between intelligence and alcoholrelated problems may differ between men and women. First, consumption of alcohol in terms of the volume and pattern of drinking differs between men and women, where men typically drink more often and in larger quantities than women. ${ }^{20}$ Second, men seem to differ from women with regard to the risk factors for and the consequences of alcohol use. For example, women are less likely to drink to reduce stress and face more severe social sanctions for drinking than men. ${ }^{21}$ Third, previous research has indicated the associations between intelligence and other health outcomes differ between men and women. For instance, men with a high IQ have been shown to have a lower risk of suicide than men with a low IQ, whereas there were no associations among women. ${ }^{22}$

How and why intelligence and health are associated is not known. Proposed hypotheses imply mainly two ways: either intelligence has effects on health, through, for example, choice in lifestyle behaviour or socioeconomic environment achieved as an adult, or, the relationship between intelligence and health is confounded by other factors such as biological or socioeconomic conditions early in life. The role played by achieved socioeconomic position in the association is intriguing. As argued by Marmot and Kivimäki, socioeconomic position as an adult is a strong candidate for being part of the explanation of how and why IQ and health are associated, since IQ strongly influences education (most), as well as profession and income (least). ${ }^{23} 24$

In a previous study, we have found a graded, inverse association between IQ in adolescent Swedish men and later risk of alcohol-related admission and death. Further, we found that socioeconomic position as an adult could be important in the association. ${ }^{25}$ Jefferis $\mathrm{et}^{\mathrm{al}} \mathrm{l}^{17}$ showed an association of low childhood cognition with nondrinking and binge drinking in the 1958 British Birth Cohort. The association found in this study between childhood cognition and non-drinking was similar for men and women, but the association differed between the genders over the life-course for binge drinking, where low cognition was more important for men in their early years (20-30 years of age) but more important for women later on in life (40 years of age). Two further studies of British cohorts, but with CAGE as outcome, found 
different results. In the 1946 British Birth Cohort, no difference was found between men and women with regard to risk of alcohol-related problems; ${ }^{15}$ but, in the 1970 British Birth Cohort study, when alcohol intake was also considered, even though there was an association among men as well as women, it was stronger in the case of women. ${ }^{10}$ In both these studies, high cognitive ability was found to be associated with high risk of both high alcohol intake and alcohol problems (CAGE). Similar results were obtained in a study from Minnesota, USA, by Johnson et al, ${ }^{16}$ where greater alcohol use was found-in men as well as women-with high IQ. In the Aberdeen Children of the 1950s study, which looked at alcohol-induced hangovers, a high IQ in childhood was associated with a lower prevalence of hangovers in middle age. The finding was similar for men and women. ${ }^{11}$ No previous study of the association between childhood IQ and later alcohol-related mortality or hospitalisation has, to the best of our knowledge, included both genders.

The use of different types of alcohol-related outcomes in previous studies might contribute to the divergence in results. In this study, we are considering alcohol-related admission and death. The outcomes in this study reflect alcohol consumption of either acute or chronic character such that the individual falls sick and is admitted to hospital or dies as a consequence of it. They are not self-rated, but assessed by healthcare personnel and, although encompassing a variety of diagnoses, are specific, being the result of consuming alcohol in a hazardous way.

The aims of this study were to (1) examine the association between IQ-test results and alcohol-related disease and death, (2) investigate whether there are any differences between men and women in such an association and (3) explore whether socioeconomic position as an adult might be a mediator in the presumed association.

\section{METHODS}

\section{Study population}

This is a cohort study with a follow-up time of 32-33 years (5 years less for the cohort born in 1953). The study population consists of 21809 Swedish individuals from the Utvärdering Genom Uppföljning (UGU/'Evaluation Through Follow-up') database. ${ }^{26}$ The UGU-database was set up for the purpose of evaluating the Swedish school system. In 1961, a series of data collections was embarked on, based on random samples of all the children born in Sweden on the 5th, the 15th or the 25th all the months of 1948. Since then, data on nine birth cohorts have been collected. For this study, we use data from individuals born in 1948 and 1953. Included in the study were participants with IQ test results from all three tests held within the UGU-project. Children who had migrated to Sweden after 7 years of age were excluded to avoid the influence of language difficulties on the IQ-test results. Individuals who had been admitted for an alcohol-related diagnosis before start of follow-up were also excluded from the analysis of alcoholrelated hospital admission (one of our outcome variables).

Record linkage between databases was made possible through the personal identification numbers assigned to every Swedish citizen.

\section{Exposure}

IQ was tested when the participants were about 13 years old, in the years 1961 and 1966, respectively. The test was performed within the classroom according to written instructions. It consists of three separate subtests: verbal, spatial and inductive, identical for both cohorts, which jointly gave a total score of
120 points. This test has also been used in another project called the Metropolit and has been tested for its reliability with a correlation of 0.78 to the Swedish military classification test. ${ }^{27-29}$ The total scores from the tests were positioned on a nine-point standard scale, which gave nine groups. ${ }^{1-9}$

\section{Outcomes}

Alcohol-related admission and death are the two outcomes in this study. The definition of alcohol-related disease was 'ever been admitted to psychiatric care with a disease that was related to alcohol' coded according to the Swedish versions of International Classification of Diseases, Revision 8 (ICD)-8, ICD-9 and ICD-10 (see online supplementary appendix 1). Examples of common diagnoses for being admitted to hospital according to this definition are habitual excessive drinking, alcohol abuse and dependence syndrome due to use of alcohol. The data on such an event were taken from the National Patient Register, which covers the years 1973-2006. Alcohol-related death was defined as the assignment of a diagnosis related to alcohol consumption, either as an underlying or a contributing cause of death, diagnoses such as, for example, alcoholism, toxic effect of alcohol or mental and behavioural disorders due to use of alcohol. Information on causes of death was obtained from the National Cause of Death Register, for the years 1973-2005. The National Patient Register and the National Cause of Death Register are both maintained by Sweden's National Board of Health and Welfare. Permission to use the data and perform record linkage was obtained from the Stockholm Regional Research Ethics Committee and the National Board of Health and Welfare.

\section{Covariates}

\section{Family background}

Information on parental socioeconomic position was collected from national population and housing censuses, the census of 1960 for the children born in 1948 and that of 1970 for the children born 1953. The socioeconomic position of the parents was categorised into (1) Non-manual employees, (2) Manual workers (3) Farmers and self-employed, and (4) Other or missing. Further, since the educational level of parents influences development, we gathered the parents' educational level from the UGU database categorised as (1) elementary and secondary school, (2) baccalaureate, (3) graduate and (4) other or missing.

Data on admission to hospital for an alcohol-related disease for any parent (mother/father) was retrieved from the National Patient Register. Further, since having divorced parents has been shown to be a risk factor for alcohol misuse, ${ }^{30}$ we included data on family composition from the national censuses of 1960 and 1965.

\section{Attained socioeconomic position}

Adult socioeconomic position was measured at age 32 on the basis of information from the national censuses of 1980 and 1985. The categories used for socioeconomic position as an adult were (1) unskilled, manual, (2) skilled, manual, (3) low, non-manual, (4) intermediate, non-manual, (5) high, nonmanual, (6) self-employed, (7) farmers and (8) other or missing.

\section{Statistical analysis}

The distributions of the covariates are described in table 1 . The relationship between IQ-test results and the two outcomes alcohol-related disease and alcohol-related death were assessed using Cox's proportional hazard model and expressed in HRs with 95\% CIs. Cox proportionality hazard assumption was assessed graphically. Censorship was defined as (1) death, (2) emigration and (3) no event during follow-up. For the outcome 
Table 1 Prevalence (\%) of risk factors, measured over the life-course, among men and women, by IQ-test result group

\begin{tabular}{|c|c|c|c|c|c|c|c|c|c|c|}
\hline & \multicolumn{9}{|c|}{ Prevalence within each group of IQ-test results (9=highest result, $1=$ lowest result) } & \multirow[b]{2}{*}{ Missing } \\
\hline & 9 & 8 & 7 & 6 & 5 & 4 & 3 & 2 & 1 & \\
\hline Men & 56.4 & 54.4 & 51.9 & 52.2 & 50.0 & 48.8 & 48 & 49.1 & 51.6 & 53.1 \\
\hline Women & 43.6 & 45.7 & 48.1 & 47.8 & 50.0 & 51.2 & 52.1 & 50.9 & 48.4 & 46.9 \\
\hline Alcohol-related admission & $1.9(14)$ & $1.1(12)$ & $1.7(43)$ & $2.6(85)$ & $3(113)$ & $3.7(112)$ & $3.9(98)$ & $6.1(77)$ & $6.6(49)$ & $4.1(74)$ \\
\hline Alcohol-related death & $0.3(2)$ & $0.4(5)$ & $0.6(14)$ & $0.5(15)$ & $0.8(30)$ & $0.6(19)$ & $0.8(21)$ & $1(13)$ & $1.1(8)$ & $0.9(17)$ \\
\hline Father's education, low & 71.10 & 75.8 & 82.3 & 86.6 & 90.8 & 91.6 & 92.6 & 94.2 & 94.1 & 79 \\
\hline Mother's education, low & 84.8 & 87.5 & 90.9 & 93.1 & 94.3 & 95.2 & 95.5 & 95.3 & 93.9 & 81.6 \\
\hline \multicolumn{11}{|l|}{ Father's SEP } \\
\hline Manual & 23.0 & 28.6 & 33 & 36.3 & 41.9 & 44.8 & 48.9 & 53.5 & 58 & 42.1 \\
\hline Non-manual & 50.7 & 47.2 & 36.1 & 34.3 & 27.1 & 23.1 & 20 & 14.4 & 9.5 & 24.3 \\
\hline \multicolumn{11}{|l|}{ Mother's SEP } \\
\hline Manual & 21.0 & 26.1 & 32 & 34.1 & 40.1 & 42.6 & 46.7 & 49.2 & 57.2 & 40.8 \\
\hline Non-manual & 58.1 & 55.5 & 44.5 & 40.6 & 34.2 & 29.3 & 26.4 & 21.6 & 15.0 & 30.0 \\
\hline Father with alcohol-related diagnosis & 1.9 & 2.6 & 2.7 & 4.0 & 3.5 & 3.7 & 4.3 & 4.9 & 4.9 & 4.8 \\
\hline Mother with alcohol-related diagnosis & 0.6 & 0.4 & 1.5 & 1.2 & 1.0 & 0.8 & 1.1 & 1.6 & 0.7 & 1 \\
\hline Divorced parents & 12.5 & 12.2 & 15.4 & 16.8 & 18.1 & 20.0 & 18.8 & 24.0 & 26.4 & 24.4 \\
\hline SEP as an adult, lowest & 7.0 & 8.3 & 11.6 & 14.4 & 19.6 & 21.9 & 29.7 & 35.4 & 38.6 & 23.1 \\
\hline Number of individuals (total) & 730 & 1126 & 2483 & 3276 & 3790 & 3071 & 2486 & 1256 & 740 & 1799 \\
\hline
\end{tabular}

alcohol-related death, the definition of death was 'other than alcohol-related'. Crude and adjusted estimates were computed for both outcomes, using PHREG SAS V.9.2 computer package. For the latter time-period, when adjusting for social position as an adult, only individuals without previous admission for an alcohol-related disease, that is, before the measuring of social position, were included. IQ-test scores grouped into the ninepoint scale (stanines) were modelled as a continuous variable.

On the basis of earlier longitudinal studies of childhood conditions and alcohol-related outcomes in Swedish cohorts, certain variables were considered as possible confounders.

To examine any difference between men and women in the association between IQ and alcohol-related disease and death, stratified analyses and an interaction term were both used.

Socioeconomic position as an adult was investigated as a possible mediator by following the methodology described by Baron and Kenny. ${ }^{31}$ We used a bootstrap method (percentile CIs) with 10000 replicates to estimate the proportion of excess risk explained by socioeconomic position as adult with $95 \%$ CIs. ${ }^{32}$ In this analysis, the programme "R" V.3.0.2 (2013-09-25)" with the bootstrap package "boot" was used.

\section{Time and follow-up}

Two different start times were used for follow-up. For both outcomes, the first follow-up started in 1973 (cohort 1948) and 1978 (cohort 1953). In order to have the same time periods with regard to age for both cohorts, the follow-up time for the second cohort (born 1953) started 5 years later. The second follow-up started in 1981 and 1986, respectively. The second start time was set at this age period, since we wanted to analyse the importance of social position as an adult. For both followups, end of follow-up was 2005 for alcohol-related deaths and 2006 for alcohol-related hospital admission.

\section{RESULTS}

The distributions of the various background characteristics by group of IQ-test result ${ }^{1-9}$ are shown in table 1 . There was a total of 1185 deaths during follow-up. Results are presented as increase in risk for either alcohol-related hospital admission or alcohol-related death per stepwise decrease on the nine-point IQ scale. In an analysis of the covariates, we found increased HRs of 2.01 (95\% CI 1.71 to 2.37) for being in a family with separated parents, 2.67 (95\% CI 2.05 to 3.47) for having a father admitted for an alcohol-related diagnosis and 1.45 (95\% CI 1.19 to 1.76 ) for having a father performing manual work, versus non-manual, for alcohol-related admission.

\section{Alcohol-related disease and death}

We identified 677 psychiatric admissions for alcohol-related disease and 144 cases of alcohol-related death during follow-up in our study populations. The risks of alcohol-related death and disease (figure 1) were both inversely associated with the results of IQ-tests in a dose-response manner. For alcohol-related

\section{Risk for alcohol-related admission and death}

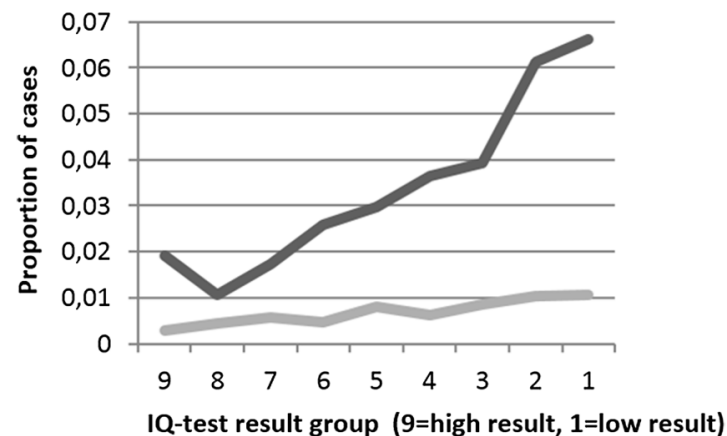

Alcohol-related admission

Alcohol-related death

Figure 1 The risk of alcohol-related admission and death by group of IQ-test result $1-9\left(R^{2}=0.88\right.$ and 0.88 , respectively). 
hospital admissions during the complete follow-up period, 1973/ 78-2005, the unadjusted HR was 1.23 (95\% CI 1.18 to 1.29 ) per each point decrease on the nine-point IQ scale. Adjusting for the covariates sex, socioeconomic position as a child, parental level of education, family composition and parent with an alcohol-related disease, had no major effect on this association (table 2). For start of follow-up 1981/1986 with adjustments for social position as adult, all previous cases of alcohol-related admission to hospital were deleted prior to analysis (table 3 ). The unadjusted $\mathrm{HR}$ remained significantly increased with a HR of 1.18 (95\% CI 1.12 to 1.25 ) per one step decrease in IQ-test result group. For alcohol-related hospital admissions, an HR of 1.22 (95\% CI 1.17 to 1.28 ), was the result of the model including all covariates. HRs per SD were also computed, for comparison. For alcohol-related admission, the HR per SD (1.94 IQ units) decrease in IQ score was unadjusted 1.50 (95\% CI 1.38 to 1.63) and for the full model 1.47 (95\% CI 1.35 to 1.61). For alcohol-related death, the unadjusted estimate was 1.28 (95\% CI 1.07 to 1.53 ) and for the full model 1.21 (95\% CI 1.00 to 1.46$)$. In the second follow-up, the model including all covariates resulted in an HR of 1.13 (95\% CI 1.06 to 1.19). Of all included covariates in our analyses, socioeconomic position as an adult attenuated the association the most.

The results on alcohol-related deaths showed a similar pattern (table 2). The unadjusted HR for the first follow-up period was 1.14 (95\% CI 1.04 to 1.24 . The model including all covariates yielded an HR of 1.10 (95\% CI 1.00 to 1.21$)$. For the second follow-up period (table 3), the unadjusted HR was 1.15 (95\% CI 1.04 to 1.27). The model including all covariates resulted in an HR of 1.04 (95\% CI 0.94 to 1.15 ).

\section{Interaction and stratification by gender}

There were 508 cases of alcohol-related admission among men and 169 cases among women. When testing for interaction for sex with an interaction variable for both outcomes, no significant difference was found. In the Cox proportional hazard model stratified by sex for the full follow-up period, the HR for alcoholrelated hospital admission was higher for men, an HR of 1.27 (95\% CI 1.21 to 1.33), than for women, HR 1.18 (95\% CI 1.08 to 1.28 ) for every step-wise change in IQ (table 2). For the latter time-period, men again had a higher HR, 1.21 (95\% CI 1.14 to 1.29) in comparison with women, HR 1.15 (95\% CI 1.05 to 1.27). When adjusting for socioeconomic position, the decrease in HR was somewhat greater for men than for women (table 3 ).

There were 107 cases of alcohol-related death in men and 37 in women. Also, for alcohol-related death, men had a higher HR, 1.17 (95\% CI 1.05 to 1.30) than women, HR 1.08 (95\% CI 0.90 to 1.29 ) in the complete time-period (table 2). In the second follow-up period, again, socioeconomic position seemed to decrease the HR to a greater extent for men, HR $1.06(95 \%$ CI 0.94 to 1.19 ) than for women, HR 1.10 (95\% CI 0.90 to 1.35) (table 3).

\section{Socioeconomic position as an adult}

To investigate the possibility that adult social position would be a mediator, we followed the analytic steps described by Baron and Kenny. ${ }^{31}$ The temporal order assumption for mediation is met. An association between IQ-results and both of the two outcomes were shown (first step). IQ was found to also be correlated with socioeconomic position as an adult (second step). Socioeconomic position was found to be associated with

Table 2 Follow-up, 1973/1978-2005/2006

\begin{tabular}{|c|c|c|c|c|c|c|}
\hline & \multicolumn{2}{|l|}{ All } & \multicolumn{2}{|l|}{ Men } & \multicolumn{2}{|c|}{ Women } \\
\hline & HR & $95 \% \mathrm{Cl}$ & HR & $95 \% \mathrm{Cl}$ & HR & $95 \% \mathrm{Cl}$ \\
\hline \multicolumn{7}{|c|}{ Alcohol-related admission ( $N=18$ 958) } \\
\hline Unadjusted & 1.23 & (1.18 to 1.29$)$ & 1.27 & (1.21 to 1.33$)$ & 1.18 & (1.08 to 1.28$)$ \\
\hline \multicolumn{7}{|l|}{ Adjusted } \\
\hline Sex & 1.24 & (1.19 to 1.30$)$ & & & & \\
\hline Father's education & 1.23 & (1.18 to 1.29$)$ & 1.26 & (1.20 to 1.33$)$ & 1.18 & (1.08 to 1.29$)$ \\
\hline Mother's education & 1.23 & (1.18 to 1.28$)$ & 1.26 & $(1.20$ to 1.32$)$ & 1.17 & (1.07 to 1.28$)$ \\
\hline Father's SEP & 1.22 & (1.17 to 1.27$)$ & 1.25 & (1.19 to 1.32$)$ & 1.17 & (1.07 to 1.28$)$ \\
\hline Mother's SEP & 1.23 & (1.17 to 1.28$)$ & 1.26 & $(1.20$ to 1.32$)$ & 1.16 & (1.07 to 1.27$)$ \\
\hline Father with alcohol diagnosis & 1.23 & (1.18 to 1.28$)$ & 1.26 & (1.20 to 1.32$)$ & 1.17 & (1.07 to 1.27$)$ \\
\hline Mother with alcohol diagnosis & 1.23 & (1.18 to 1.29$)$ & 1.27 & (1.21 to 1.33$)$ & 1.18 & (1.08 to 1.28$)$ \\
\hline Family composition & 1.22 & (1.17 to 1.27$)$ & 1.26 & (1.20 to 1.32$)$ & 1.16 & (1.06 to 1.26$)$ \\
\hline Full model* & 1.22 & (1.17 to 1.28$)$ & 1.25 & (1.19 to 1.32$)$ & 1.13 & (1.03 to 1.25$)$ \\
\hline \multicolumn{7}{|l|}{ Alcohol-related death $(N=19005)$} \\
\hline Unadjusted & 1.14 & (1.04 to 1.24$)$ & 1.17 & (1.05 to 1.30$)$ & 1.08 & (0.90 to 1.29$)$ \\
\hline \multicolumn{7}{|l|}{ Adjusted } \\
\hline Sex & 1.15 & (1.05 to 1.25$)$ & & & & \\
\hline Father's education & 1.14 & (1.03 to 1.25$)$ & 1.17 & (1.05 to 1.31$)$ & 1.06 & (0.88 to 1.29$)$ \\
\hline Mother's education & 1.12 & (1.02 to 1.22$)$ & 1.15 & (1.03 to 1.28$)$ & 1.06 & (0.88 to 1.28$)$ \\
\hline Father's SEP & 1.11 & (1.01 to 1.22$)$ & 1.15 & (1.04 to 1.28$)$ & 1.05 & (0.87 to 1.26$)$ \\
\hline Mother's SEP & 1.12 & (1.02 to 1.23$)$ & 1.16 & (1.04 to 1.29$)$ & 1.08 & (0.90 to 1.30$)$ \\
\hline Father with alcohol diagnosis & 1.13 & (1.04 to 1.24$)$ & 1.17 & (1.05 to 1.30$)$ & 1.07 & (0.89 to 1.29$)$ \\
\hline Mother with alcohol diagnosis & 1.13 & (1.04 to 1.24$)$ & 1.17 & (1.05 to 1.30$)$ & 1.08 & (0.90 to 1.29$)$ \\
\hline Family composition & 1.11 & (1.01 to 1.21$)$ & 1.15 & (1.04 to 1.28$)$ & 1.04 & (0.87 to 1.26$)$ \\
\hline Full model* & 1.10 & (1.00 to 1.21$)$ & 1.14 & (1.02 to 1.28$)$ & 0.99 & (0.81 to 1.21$)$ \\
\hline
\end{tabular}


Table 3 Follow-up, 1981/1986-2005/2006

\begin{tabular}{|c|c|c|c|c|c|c|}
\hline & \multicolumn{2}{|l|}{ All } & \multicolumn{2}{|l|}{ Men } & \multicolumn{2}{|c|}{ Women } \\
\hline & HR & $95 \% \mathrm{Cl}$ & HR & $95 \% \mathrm{Cl}$ & HR & $95 \% \mathrm{Cl}$ \\
\hline \multicolumn{7}{|c|}{ Alcohol-related admission ( $N=18$ 825) } \\
\hline Unadjusted & 1.18 & (1.12 to 1.25$)$ & 1.21 & (1.14 to 1.29$)$ & 1.15 & (1.05 to 1.27$)$ \\
\hline \multicolumn{7}{|l|}{ Adjusted } \\
\hline Sex & 1.20 & (1.14 to 1.26$)$ & & & & \\
\hline Father's education & 1.19 & (1.13 to 1.25$)$ & 1.21 & (1.14 to 1.29$)$ & 1.15 & (1.04 to 1.28$)$ \\
\hline Mother's education & 1.18 & (1.12 to 1.24$)$ & 1.20 & (1.13 to 1.28$)$ & 1.14 & (1.03 to 1.26$)$ \\
\hline Father's SEP & 1.17 & (1.11 to 1.23$)$ & 1.20 & (1.13 to 1.27$)$ & 1.15 & (1.04 to 1.27$)$ \\
\hline Mother's SEP & 1.18 & (1.12 to 1.24$)$ & 1.21 & (1.13 to 1.28$)$ & 1.14 & (1.03 to 1.26$)$ \\
\hline Father with alcohol diagnosis & 1.18 & (1.12 to 1.24$)$ & 1.21 & (1.14 to 1.28$)$ & 1.15 & (1.04 to 1.27$)$ \\
\hline Mother with alcohol diagnosis & 1.18 & (1.12 to 1.25$)$ & 1.21 & (1.14 to 1.29$)$ & 1.15 & (1.05 to 1.27$)$ \\
\hline Family composition & 1.17 & (1.11 to 1.24$)$ & 1.21 & (1.14 to 1.28$)$ & 1.13 & (1.02 to 1.24$)$ \\
\hline SEP as adult & 1.13 & (1.07 to 1.19$)$ & 1.14 & (1.07 to 1.22$)$ & 1.12 & (1.01 to 1.24$)$ \\
\hline Full model except SEP as adult* & 1.18 & (1.11 to 1.24$)$ & 1.21 & (1.13 to 1.29$)$ & 1.11 & (0.99 to 1.23$)$ \\
\hline Full model & 1.13 & (1.07 to 1.20$)$ & 1.15 & (1.08 to 1.23$)$ & 1.09 & (0.97 to 1.21$)$ \\
\hline \multicolumn{7}{|l|}{ Alcohol-related death $(N=18987)$} \\
\hline Unadjusted & 1.15 & (1.04 to 1.27$)$ & 1.17 & (1.04 to 1.31$)$ & 1.13 & (0.93 to 1.37$)$ \\
\hline \multicolumn{7}{|l|}{ Adjusted } \\
\hline Sex & 1.16 & (1.05 to 1.28$)$ & & & & \\
\hline Father's education & 1.14 & (1.03 to 1.26$)$ & 1.16 & (1.03 to 1.31$)$ & 1.12 & (0.91 to 1.38$)$ \\
\hline Mother's education & 1.13 & (1.02 to 1.24$)$ & 1.15 & (1.02 to 1.29$)$ & 1.11 & (0.91 to 1.36$)$ \\
\hline Father's SEP & 1.12 & (1.01 to 1.24$)$ & 1.15 & (1.02 to 1.28$)$ & 1.09 & (0.90 to 1.34$)$ \\
\hline Mother's SEP & 1.13 & (1.02 to 1.25$)$ & 1.15 & (1.03 to 1.29$)$ & 1.12 & (0.91 to 1.37$)$ \\
\hline Father with alcohol diagnosis & 1.14 & (1.04 to 1.26$)$ & 1.17 & (1.04 to 1.31$)$ & 1.12 & (0.92 to 1.36$)$ \\
\hline Mother with alcohol diagnosis & 1.15 & (1.04 to 1.26$)$ & 1.17 & (1.04 to 1.31$)$ & 1.13 & (0.93 to 1.36$)$ \\
\hline Family composition & 1.12 & (1.02 to 1.24 & 1.15 & (1.03 to 1.29$)$ & 1.09 & (0.89 to 1.33$)$ \\
\hline SEP as adult & 1.06 & (0.96 to 1.18 & 1.06 & (0.94 to 1.19$)$ & 1.10 & (0.90 to 1.35$)$ \\
\hline Full model except SEP as adult & 1.10 & (0.99 to 1.23 & 1.13 & (1.01 to 1.28$)$ & 1.03 & (0.83 to 1.28$)$ \\
\hline Full model & 1.04 & (0.94 to 1.15 & 1.04 & (0.92 to 1.19$)$ & 1.02 & (0.81 to 1.28$)$ \\
\hline
\end{tabular}

alcohol-related hospital admission and death, when adjusted for IQ (third step). At the fourth step, when analysing the effect of IQ on both outcomes while controlling for socioeconomic position, the association for alcohol-related hospital admission suggested partial mediation. From the bootstrap analysis, the excess risk explained by socioeconomic position as adult was found to be 0.29 (95\% CI 0.18 to 0.45 ) for the whole population using the formula $1-\left[\ln H R_{\mathrm{A}} / \ln \mathrm{HR}_{\mathrm{U}}\right]=1-\left[\beta_{1 \mathrm{~A}} / \beta_{1 \mathrm{U}}\right]$, for a multiplicative model. ${ }^{33}$ In separate analysis for men, the estimate was found to be 0.28 (95\% CI 0.16 to 0.45 ) and for women 0.26 (95\% CI 0.04 to 0.93 ). However, our interpretation of the analysis made on women is that the data is skewed to the extent that the results are unreliable. This is probably due to the low number of cases for women.

For alcohol-related death, the association was no longer significant, which in this formal investigation indicates complete mediation.

\section{DISCUSSION}

We found an increased risk of alcohol-related hospital admission $(\mathrm{HR}=1.23,95 \%$ CI 1.18 to 1.29$)$ for every step decrease from high IQ-test result group, to low. Similar results, albeit of a lesser magnitude, were found for alcohol-related death (HR $1.14,95 \%$ CI 1.04 to 1.24$)$. Social position as an adult attenuated the association the most, while, for example, parental socioeconomic position and parental level of education did not seem to have any great effect. When adjusting for socioeconomic position as adult, it is necessary to be aware of the possibility of over-adjustment, given the importance of IQ for later education, profession and income. An increase in 1.23 per each point decrease on the nine-point IQ scale gives a difference in HR of 5.24, between those with highest results and those with the lowest, for alcohol-related admission.

As mentioned above, studies of the association between intelligence and alcohol-related problems have produced conflicting results. The findings in the current study are in line with those of one of our previous studies, which had the same outcomes. ${ }^{25}$ There are several types of alcohol-related outcomes used in previous research (pattern of drinking, frequency of drinking, hangovers, etc), which could partly be an explanation of the diverging results. It is possible that measures of alcohol-related self-assessments might pick up other spectra of alcohol consumption than, for instance, clinical diagnoses do.

Social position as an adult was found to be a partial mediator of alcohol-related disease and a complete mediator for alcoholrelated death in our causal steps analysis. Our finding on the role of acquired socioeconomic position as an adult is in line with earlier studies. ${ }^{11}{ }^{14}$ It does seem that socioeconomic position has less importance for women than for men. Overall, our study provides support for the suggested pathway that runs from intelligence through socioeconomic position to health. Our results do not, however, provide full explanation for the 
mechanism between IQ and alcohol-related admission and death. Clearly, other factors could still be involved. Neither do our results tell about how socioeconomic position affects the risk of alcohol-related admission and death by IQ. The importance of socioeconomic position for health has been shown in numerous studies and several theories have been presented to explain health inequalities. ${ }^{34}$ IQ could be expected to influence several of the suggested explanations, such as material conditions, as well as psychosocial and behavioural factors.

Adjusting for socioeconomic position as a child did not alter the estimate noteworthy; for the outcomes used in this study, the pathway originating in childhood conditions is less probable. This finding is in accordance with previous research. ${ }^{19}$

In general, men showed a greater risk of alcohol-related admission and death than women, which is in accordance with previous research. Yet, when testing, no interaction for sex was found in the investigated associations. The results regarding differences between men and women are consistent with those of Batty et al,${ }^{11}$ who looked at alcohol-induced hangovers. In three studies where associations were found inverse to our results, they were similar for both sexes, although the effects were stronger for women in one of them. ${ }^{10} 1516$ Again, since the outcomes in these studies are different from those used in the present study, comparisons have to be made with care. Given the background of the differences between the sexes in alcohol consumption, risk factors for alcohol problems, and previously found association between IQ and mortality, it is rather surprising that no interaction was found. However, the previous literature that has examined differences between the sexes suggests that the association may differ over the life course. ${ }^{17}$

\section{Strengths and limitations}

This is a longitudinal cohort study with a study population and follow-up period sufficient to assess the effects of IQ on alcohol-related outcomes later in life. The individuals concerned were not self-selected, but randomly drawn from the general population. No information was collected after the outcomes were measured, which reduces the risk of recall bias. There is a small likelihood of reverse causality, since the exposure was measured as such a young age. Also, we were able to control for several known possible confounders, at different time points in life. Further, we had the opportunity to analyse data on women, about whom there is a lack of knowledge in this area.

*There are several limitations to our study. There is the possibility of misclassification of the outcomes, since there may be under-reporting of alcohol-related diagnoses. Such underreporting might be even higher among individuals with high IQ-test results, which would lead to an exaggeration of the effect. The proportion of cases for both outcomes differed between the genders. Given the greater consumption of alcohol among men than among women, this was to be expected. ${ }^{20}$ However, the few cases of alcohol-related disease and death among women reduced the statistical power to detect any clear pattern of association in women. In this study, we focused on socioeconomic position as an adult as a possible mediator between IQ and health, which is one of the explanatory models put forth within cognitive epidemiology. We were able to use 'achieved socioeconomic position' at age 32, which from a working life perspective is a young age; however, changes could be expected over the life-course. Although we were able to adjust for socioeconomic conditions as a child, which is one variable suggested to explain the association between IQ and health, other factors could still confound the association. A psychiatric condition, which could affect both IQ-test result and risk for alcohol-related disease, would be such a possible confounder. Other factors related to alcohol consumption (pattern, volume and frequency of drinking) would also be of interest. We were not able to adjust for any of these possibly important confounders in this study.

\section{CONCLUSIONS}

There appears to be an inverse, graded association between IQ measured in childhood and later risk of alcohol-related admission. The association can be characterised as a dose-response relationship. The association between IQ measured in childhood and later risk of alcohol-related admission was stronger among men and women, although no interaction for gender was found. Adult socioeconomic position was found, at least partially, to mediate this association. The same pattern can be seen for alcohol-related death, although not statistically significantly.

\section{What is already known on this subject?}

- Intelligence has been shown to be inversely associated with several health outcomes.

- The associations between intelligence and alcohol-related outcomes have shown divergent results.

\section{What this study adds?}

- We found an association between intelligence and alcohol-related admission, and mortality among men and women.

- We did not find an interaction for gender in the association.

- Socioeconomic position as an adult seems to at least partially mediate in the association.

Acknowledgements The authors are grateful to Åsa Berntsson and Sofia Löfving for their help with management of the data and to Linnea Widman for assisting in the bootstrapping analysis.

Contributors All authors have contributed to the conception and design of the study as well as collection of data from various sources. SS performed the analyses. All authors were involved in text editing and discussion of findings. All authors have approved of the final version of the manuscript.

Funding The work was supported by a grant from the Swedish Research Council on Working Life and Social Sciences (FAS) (Grant number 2009-1611).

\section{Competing interests None.}

Ethics approval The Regional Ethical Review Board in Stockholm.

Provenance and peer review Not commissioned; externally peer reviewed.

Open Access This is an Open Access article distributed in accordance with the Creative Commons Attribution Non Commercial (CC BY-NC 4.0) license, which permits others to distribute, remix, adapt, build upon this work non-commercially, and license their derivative works on different terms, provided the original work is properly cited and the use is non-commercial. See: http://creativecommons.org/ licenses/by-nc/4.0/

\section{REFERENCES}

1 Hemmingsson $T$, Melin B, Allebeck $\mathrm{P}$, et al. The association between cognitive ability measured at ages 18-20 and mortality during 30 years of follow-up-a prospective observational study among Swedish males born 1949-51. Int J Epidemiol 2006:35:665-70.

2 Calvin CM, Deary IJ, Fenton C, et al. Intelligence in youth and all-cause-mortality: systematic review with meta-analysis. Int J Epidemiol 2011;40:626-44. 
3 Batty GD, Mortensen EL, Nybo Andersen AM, et al. Childhood intelligence in relation to adult coronary heart disease and stroke risk: evidence from a Danish birth cohort study. Paediatr Perinat Epidemiol 2005;19:452-9.

4 Batty GD, Mortensen LH, Gale CR, et al. IQ in late adolescence/early adulthood, risk factors in middle age, and later cancer mortality in men: the Vietnam Experience Study. Psychooncology 2009;18:1122-6.

5 Batty GD, Mortensen EL, Osler M. Childhood IQ in relation to later psychiatric disorder: evidence from a Danish birth cohort study. Br J Psychiatry 2005;187:180-1.

6 David AS, Malmberg A, Brandt L, et al. IQ and risk for schizophrenia: a population-based cohort study. Psychol Med 1997;27:1311-23.

7 Der G, Batty GD, Deary IJ. The association between IQ in adolescence and a range of health outcomes at 40 in the 1979 US National Longitudinal Study of Youth. Intelligence 2009;37:573-80.

8 Gale CR, Batty GD, Tynelius P, et al. Intelligence in early adulthood and subsequent hospitalization for mental disorders. Epidemiology 2010;21:70-7.

9 Zammit S, Allebeck P, David AS, et al. A longitudinal study of premorbid IQ Score and risk of developing schizophrenia, bipolar disorder, severe depression, and other nonaffective psychoses. Arch Gen Psychiatry 2004;61:354-60.

10 Batty GD, Deary IJ, Schoon I, et al. Childhood mental ability and adult alcohol intake and alcohol problems: the 1970 British cohort study. Am J Public Health 2008;98:2237-43.

11 Batty GD, Deary IJ, Macintyre S. Childhood IQ and life course socioeconomic position in relation to alcohol induced hangovers in adulthood: the Aberdeen children of the 1950s study. J Epidemiol Community Health 2006;60:872-4.

12 David AS, Zammit $S$, Lewis $G$, et al. Impairments in cognition across the spectrum of psychiatric disorders: evidence from a Swedish conscript cohort. Schizophr Bull 2008;34:1035-41.

13 Fergusson DM, Horwood LJ, Ridder EM. Show me the child at seven II: Childhood intelligence and later outcomes in adolescence and young adulthood. I Child Psychol Psychiatry 2005;46:850-8.

14 Gale CR, Deary IJ, Boyle SH, et al. Cognitive ability in early adulthood and risk of 5 specific psychiatric disorders in middle age: the Vietnam experience study. Arch Gen Psychiatry 2008;65:1410-18.

15 Hatch SL, Jones PB, Kuh D, et al. Childhood cognitive ability and adult mental health in the British 1946 birth cohort. Soc Sci Med 2007;64:2285-96.

16 Johnson W, Hicks BM, McGue M, et al. How Intelligence and Education Contribute to Substance Use: Hints from the Minnesota Twin Family Study. Intelligence 2009;37:613-24.

17 Jefferis BJ, Manor O, Power C. Cognitive development in childhood and drinking behaviour over two decades in adulthood. J Epidemiol Community Health 2008:62:506-12.
18 Mortensen LH, Sorensen TI, Gronbaek M. Intelligence in relation to later beverage preference and alcohol intake. Addiction 2005;100:1445-52.

19 Batty GD, Deary IJ, Gottfredson LS. Premorbid (early life) IQ and later mortality risk: systematic review. Ann Epidemiol 2007;17:278-88.

20 Wilsnack RW, Vogeltanz ND, Wilsnack SC, et al. Gender differences in alcohol consumption and adverse drinking consequences: cross-cultural patterns. Addiction 2000;95:251-65.

21 Nolen-Hoeksema S. Gender differences in risk factors and consequences for alcohol use and problems. Clin Psychol Rev 2004;24:981-1010.

22 Andersson L, Allebeck P, Gustafsson JE, et al. Association of IQ scores and school achievement with suicide in a 40-year follow-up of a Swedish cohort. Acta Psychiatr Scand 2008;118:99-105.

23 Marmot M, Kivimaki M. Social inequalities in mortality: a problem of cognitive function? Eur Heart J 2009;30:1819-20.

24 Gottfredson LS. Intelligence and Social Inequality Why the Biological Link? In: Chamorro-Premuzic T, von Stumm S, Furnham A, eds. The Wiley-Blackwell handbook of individual differences. Blackwell Publishing Ltd., 2011:538-75.

25 Sjolund S, Allebeck P, Hemmingsson T. Intelligence quotient (IQ) in adolescence and later risk of alcohol-related hospital admissions and deaths-37-year follow-up of Swedish conscripts. Addiction 2012;107:89-97.

26 Härnqvist K. Evaluation through follow-up. A longitudinal program for studying education and career development. Department of Education and Educational Research, 2000.

27 Harnqvist K. Relative changes in intelligence from 13 to 18. I. Background and methodology. Scand J Psychol 1968;9:50-64.

28 Harnqvist K. Relative changes in intelligence from 13 to 18. II. Results. Scand J Psychol 1968;9:65-82.

29 Jansson C-G. Project Metropolitan. Acta Sociologica 1966:9:110-15.

30 Huurre T, Lintonen T, Kaprio J, et al. Adolescent risk factors for excessive alcohol use at age 32 years. A 16-year prospective follow-up study. Soc Psychiatry Psychiatr Epidemiol 2010;45:125-34.

31 Baron RM, Kenny DA. The moderator-mediator variable distinction in social psychological research: conceptual, strategic, and statistical considerations. J Pers Soc Psychol 1986;51:1173-82

32 DiCiccio TJ, Efron B. Bootstrap confidence intervals. Stat Sci 1996;11:189-228.

33 Brotman DJ. Mediators of the association between mortality risk and socioeconomic status. JAMA 2006;296:763-4; author reply 4.

34 Skalicka V, van Lenthe F, Bambra C, et al. Material, psychosocial, behavioural and biomedical factors in the explanation of relative socio-economic inequalities in mortality: evidence from the HUNT study. Int J Epidemiol 2009;38:1272-84. 